Transiated from Izvestiya Akademii Nauk SSSR, Otdelenie Khimicheskikh Nauk, No. 12, pp. 2080-2081, December, 1960

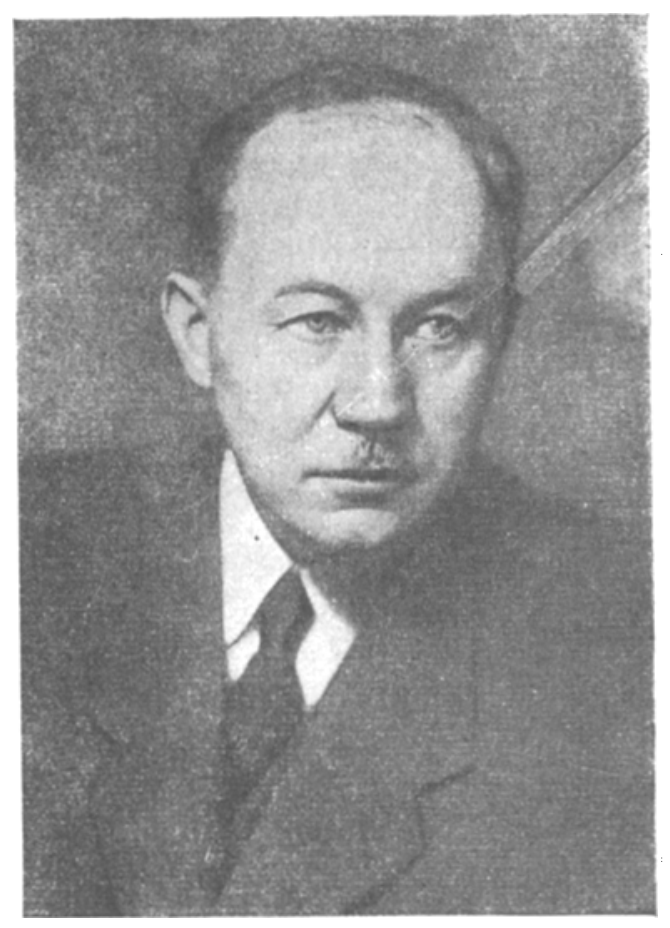

\section{ANATOLII FEDOROVICH KAPUSTINSKII}

Soviet chemical science has suffered a great loss. Corresponding Member of the Acad. Sci. USSR Anatolii Fedorovich Kapustinskii, an outstanding Soviet chemist has died prematurely at the age of 54 . His name is connected with a series of broad generalizations in the field of inorganic and physical chemistry. His lucid and very original investigations gave results which were outstanding in simplicity and cogency. Kapustinskii's work combined the methods of structural chemistry and thermodynamics. This combination was a particular feature of his extensive contributions to chemical science.

A. F. Kapustinskii was born on December 29, 1906 in Zhitomir. In 1914 he entered the Warsaw primary gymnasium and in 1922 finished a secondary school in Moscow. In 1923 he became a student in the chemical section of the Physics and Mathematics Department of Moscow State University. In 1929 he graduated from the chemical department of the university. Kapustinskii was the student of the esteemed Academician I. A. Kablukov and Academician E. V. Britske. After completing his university studies, Kapustinskii worked from 1929 to 1941 in the Institute of Applied Mineralogy (now the All-Union Institute of Raw Material) in Moscow, first as laboratory assistant in E. V. Britske's laboratory and then as a candidate, as an engineer, as senior scientist, director of the laboratory and then of the section, and as scientific consultant. In 1935 he was sent to western Europe and the USA. He worked for half a year in the laboratory of G. N. Lewis at the University of California. In 1939 at the age of 33 Kapustinskii was elected Corresponding Member of the Academy of Scierices of the USSR in the Division of Chemical Sciences. In 1941 he transferred to the Academy of Sciences USSR to work in the Institute of General and Inorganic Chemistry.

Kapustinskii's teaching activities started in 1930 in the department of physical chemistry of the Moscow higher Technical Institute. In the following years he became professor and director of the department of physical chemistry of Gor' kii State University (1933-1937), the Moscow Steel Institute (1937-1941), and Kazan State University (19411943). In 1943 he was elected professor in in charge of the department of general and inorganic chemistry of the D. I. Mendeleev Moscow Chemicotechnological Institure and he worked there till the end of his life. Kapustinskii was a remarkable orator and excellent lecturer. The numerous students and all who heard him will always remember his lectures and reports, which were brilliant both in content and form.

Kapustinskiïs work covered an exeptionally wide range. He carried out a large number of investigations on many very important problems of chemistry. We should mention his work on the thermodynamics of metallurgical processes, crystal chemistry and especially the energetics of crystals, heats of formation of inorganic compounds, theoretical work on problems of the Periodic Law, geochemistry, solvation of ions in solutions, and the history of chemistry. The list of his works includes 350 titles. His best known work is that connected with problems of crystal chemistry. The equation he derived for the lattice energy of an ionic crystal $(1933,1943$, and 1956) is given in all monographs and textbooks on crystal chemistry. In 1934 he introduced the very important concept of "thermochemical radii" of ions, which was particularly valuable in investigations of complex ions. In $1949 \mathrm{~A}$. F. Kapustinskii proposed a new ionic constant, that of "crystallochemical electronegativity," which characterizes the electronic affinity of an ion in a crystal. In 1956 he derived a very simple equation which related such fundamental characteristics of ions in crystals as the radius, the charge, and the total number of electrons. 
Kapustinskii's investigations throw light upon the most general and fundamental problems of chemistry. Thus, he was able to extend one of the most general laws of chemistry, Avogadro's Law, to cover the electronic structure of atoms and ions. In his investigations of the solvation of ions in solutions, Kapustinskii worked out a theory of quantitative characteristics of individual ions in solution and this made it possible for him to derive a single system for the entropy and radii of ions in aqueous solutions, as well as to propose an electronic mechanism for the hydration of ions in solutions.

His activity in the publishing field and popularization of science was very varied and fruitful. For almost twenty years he was a member and vice-chairman of the Editorial Board of the journal "Izvestiya Akademii Nauk SSSR, Otdelenie Khimicheskikh Nauk." In 1946 he became a member of the Main Editorial Board of the second edition of the Large Soviet Encyclopedia and headed the section on chemistry. He was editor of translated foreign monographs and textbooks. From 1957 Kapustinskii was chairman of the National Union of Soviet Historians of Chemistry. In 1960 he was elected honorary member of the Polish Chemical Society. For his outstanding contributions to the development of chemical science he was awarded the Order of the Red Labor Banner and medals. All those who knew the outstanding Soviet scientist and remarkable man Anatolii Fedorivich Kapustinskii, will always remember him. 